J. Lake Sci. (湖泊科学), $2006, \mathbf{1 8}(5): 490-494$

http:// www. jlakes. org. E-mail: jlakes@ niglas. ac.cn

(c) 2006 by Journal of Lake Sciences

\title{
西太湖湖滨典型河网区与太湖水量的交换”
}

\author{
庄 巍, 逢 勇
}

(河海大学环境科学与工程学院,南京 210098)

摘 要: 以西太湖湖滨典型河网区一一宜兴大浦河网区为研究区域, 对于该典型河网区与太湖之间的水量交换情况进行 了系统的计算研究. 考虑降雨因素的影响,采用考虑下垫面分类的产汇流模型,对各计算年内(2002 年(基准年),1998 年 (丰水年),1995 年(平水年),1994 年(枯水年) ) 典型河网区及其西部山地区域的降雨径流过程进行了产汇流模拟. 建立 起适合该河网区域的非稳态河网水量模型,结合径流计算结果,对各年内典型河网区内水流的动态变化进行了计算模拟, 对典型河网区与太湖水体的水量交换情况进行系统研究, 分别对顺流与逆流情况下交换水量的年内分布与年际变化规律 进行了分析.

关键词:河网区;水量模型;产汇流模型;水量交换;太湖

\section{Water quantity exchanges between typical river network area and western Lake Taihu}

\section{ZHUANG Wei \& PANG Yong}

( College of Environmental Science and Engineering, Hohai University, Nanjing 210098, P. R. China)

\begin{abstract}
The study focused on the water quantity exchanges between the typical river network area (at Dapu Town, Yixing City) and the western Lake Taihu. Effect of rainfall taken into consideration, the runoff formation and flow concentration model considering various underlying surfaces was adopted to simulate the runoff process, both of the typical river network area and the nearby western hill area (2002 (base year) ,1998 (wet year) , 1995 (normal year) and 1994(dry year) respectively). Then the non-steady state river network water quantity model was established by adapting to the typical river network area. Combined with the results of the runoff formation and flow concentration simulation, the water quantity model was applied to simulate the dynamic changes of water flow in the typical river network area, for each year mentioned respectively. Finally, water quantity exchanges between the typical river network area and the western Lake Taihu was ascertained. Changes of the water quantity exchanges in the year and between the years was also studied, on both co-current and adverse current conditions.
\end{abstract}

Keywords : River network area; water quantity model; runoff generation and concentration model; water quality exchanges; Lake Taihu

环太湖河道与太湖的水量及污染物交换问题一直备受关注, 水利、环境学者们对此已开展了一些相关 的研究工作 ${ }^{[1-4]}$, 但系统性的研究相对较少. 太湖地区河道多为往复流动, 在此水量条件下形成了更为复 杂的水质条件,故研究环太湖河道与太湖之间的水量交换具有基础性意义. 本文以西太湖湖滨的宜兴大浦 典型河网区为研究区域,对该湖滨河网区与太湖间的水量交换关系进行了研究和探讨.

地处西太湖湖滨带的宜兴市大浦镇, 属太湖流域蟙河水系, 地势平坦,水网密布, 为典型的平原河网区. 该区域东濒太湖, 北承东氿湖, 南接河网平原,西临丘陵山地, 周边地形及水系构成较为复杂 (图 1). 国家 “十五”重大科技项目——“湖面源污染控制成套技术课题研究示范工程” 的示范工程区设在大浦镇, 目 前在大浦河网区内建立了面源污染削减控制示范工程, 拟通过面源污染物削减控制、水体净化强化等多项

* 国家高技术研究发展计划 (863 计划) “河网区面源污染控制成套技术(2002AA601012)”、国家自然科学基金“太湖 蓝藻水华形成机理及模拟研究 (50579015)”联合资助. 2005-10-26 收稿;2006-01-20 收修改稿. 庄巍, 男,1981 年生,博士研究生;E-mail: zhuangv@ sina. com. 
工程措施, 实现对河网区内水环境的改善. 这些污染控制工程对水流流态及流速的依赖性均较高, 而河网 区内的水流条件十分复杂:受太湖、东氿湖水位影响,河网区内水流流向顺逆不定 (常年流态为承东氿湖来 水,由东部汇人太湖,但也存在太湖湖水涨漫倒灌人河网区的情况); 在雨期受西部山区径流及河网区自产 径流的影响较大;加之河网区内河网密布、闸口圩坝众多,各河道的水流条件呈复杂变化 ${ }^{[3-5]}$.

本文以该典型河网区为研究核心,对各典型年内 (2002 年(基准年),1998 年(丰水年),1995 年 (平水 年),1994 年(枯水年)) 典型河网区与西部山区、周边河网区以及东部太湖区之间的水力联系规律进行了系 统研究. 对于西部山区径流来水过程、河网区自产水过程采用产汇流模型进行研究; 对于典型河网区与太 湖及周边水体的水力联系规律, 则结合降雨径流计算结果, 采用河网非稳态水量模型进行研究. 在此基础 上, 通过研究两条主要人湖河道林庄港、朱渎港的水体流动规律, 考察了典型河网区与东部太湖区之间的水 量交换情况, 分别对顺流与逆流情况下交换水量在年内分布及年际间变化规律分别进行了分析.

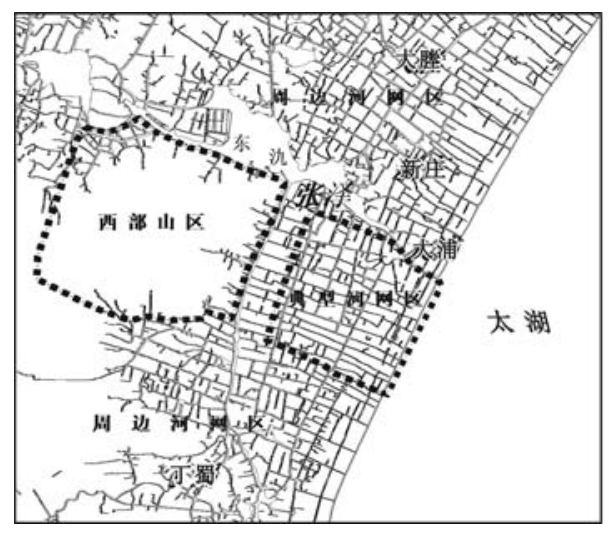

图 1 研究区域水系概况

Fig. 1 Distribution graph of the water system of the research zone

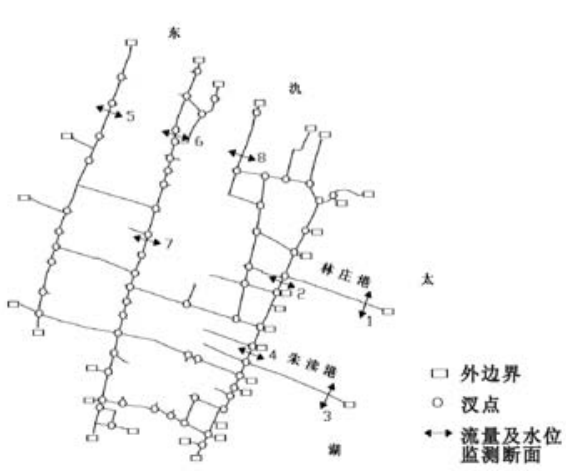

图 2 典型河网区河网概化图

Fig. 2 Generalized graph for the typical river network area

\section{1 模型建立}

\section{1 产汇流模型}

考虑到不同下垫面产流方式的差异性,对于不同下垫面采用其对应的产流模式,按照下垫面组成进行 加权计算. 汇流计算根据地形特点, 考虑水量调蓄、调度等因素, 采用瞬时单位线法、经验汇流曲线法等进 行计算 ${ }^{[6,7]}$. 产汇流参数均由文献 $[7]$ 的研究成果确定.

\section{2 河网水量模型}

1.2.1 基本方程及求解 ${ }^{[8,9]}$ 描述明渠一维非恒定流动的圣维南方程组包括连续方程与运动学方程:

$$
\begin{aligned}
& \frac{\partial Q}{\partial x}+B T \frac{\partial Z}{\partial t}=q \\
& \frac{\partial Q}{\partial t}+\frac{\partial}{\partial x}\left(\frac{Q^{2}}{A}\right)+g A \frac{\partial Z}{\partial x}+g A \frac{Q|Q|}{K^{2}}=0
\end{aligned}
$$

式中, $Z$ 为水位; $Q$ 为流量; $K$ 为流量模数; $q$ 为单位河长旁侧入流; $A$ 为主槽过水断面面积; $g$ 为重力加速度; $x$ 为沿水流方向距离; $t$ 为时间 $; B_{T}$ 为调蓄宽度,指包括滩地在内的全部河宽.

水流运动在河网各节点上应满足质量守恒及能量守恒两个连接条件:

$$
\begin{aligned}
& \sum_{i=1}^{m} Q_{i}=\left(\Omega_{K}^{+1}\right)-\Omega_{K}^{j} / \Delta t \\
& Z_{i}=Z_{j}(i, j=1,2, \cdots, m)
\end{aligned}
$$

式中, $K$ 为汉点编号; $m$ 为流人 (流出) 第 $\mathrm{K}$ 个汊点的河道数量; $\Omega_{K}$ 为汊点蓄量; $Q_{i}$ 为第 $i$ 条河道流人汊点的 
流量.

以 Preissmann 四点隐式差分格式将方程组离散 ${ }^{[10]}$, 辅以连接条件, 形成河道方程, 以微段、河段、汉点 三级联解的方法 ${ }^{[1]}$ 求解. 另外采用 Muler 法 ${ }^{[12]}$ 给出的嵌套迭代法提高计算精度.

1.2 .2 参数率定 于 2004 年 3 月 5 日 - 7 日在典型河网区内进行了水位水量的同步监测, 根据监测所得河 网区各边界的水文条件, 对已建立的河网区河网模型 (河网概化图见图 2) 进行了参数率定. 率定得河道糙 率取值范围为 $0.018-0.037$, 计算值和实测值的对比结果表明 (图 3), 模型计算值和实测值基本吻合, 说 明所建模型可用来描述研究区域水量的变化规律.
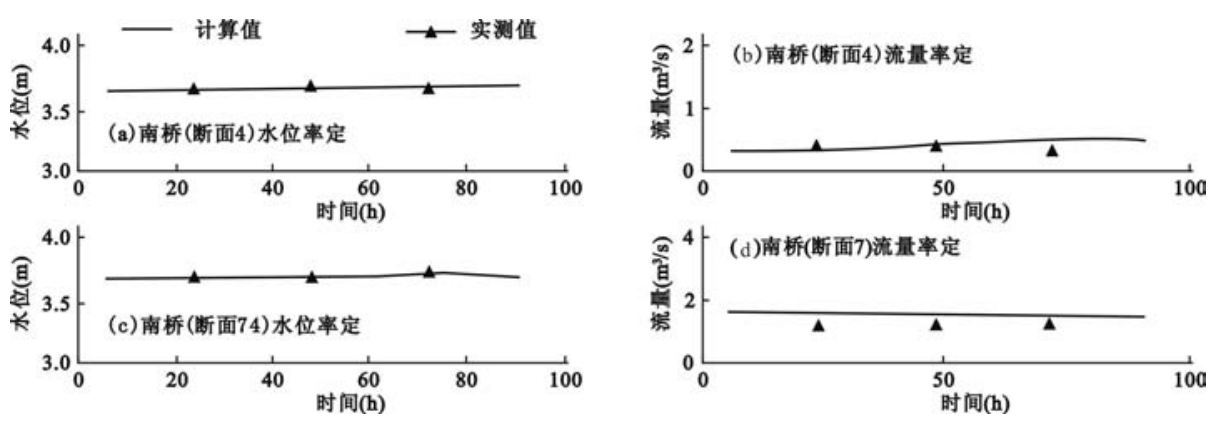

图 3 水位、水量率定结果

Fig. 3 Results of water level and water flow calibration

\section{2 典型河网区、西部山区降雨径流研究}

\section{1 计算方法 ${ }^{[6,7]}$}

根据 2002 年(基准年)、1998 年(丰水年)、1995 年(平水年) 及 1994 年(枯水年)湖滏、杨省庄、善卷及 大浦口各站的逐日降雨量资料, 宜城站逐日蒸发量资料, 结合水量调蓄措施、防汛调度方案等, 计算模拟了 各计算年内的典型河网区降雨产水汇流过程及西部山区产水汇人典型河网区的径流过程. 分水面、水田、 旱地及不透水面积四种下垫面类型进行产流计算, 分河网区与山区两种地形进行径流计算.

对于典型河网区,鉴于其圩坝相隔的特点,按照子河网区划分了计算分区,根据河网区防汛调度方案建 立汇流出流过程模式. 对于西部山地区, 出流过程采取地区综合的单位过程线进行确定.

\section{2 径流计算结果分析}

由径流计算结果可知 (图 4), 在各计算年限中,典型河网区自产水量与西部山区人流水量的值于丰水 年、平水年、枯水年内依次递减, 基准年内的值最大; 径流量主要集中发生于各年的丰水期内, 平水期内产生 量较少,枯水期内极少. 总体上典型河网区自产水量大于山区来水量.

\section{3 典型河网区河网与东部太湖区水量交换研究}

\section{1 计算方法}

根据典型河网区河网的水文特征及调度需求,典型河网区内共概化河道 151 条 (其中外边界河道 30 个, 内边界河道 39 个), 汉点 71 个, 共划分河道断面 494 个(图 2). 研究区域的西部边界由产汇流模型计算 得到. 北部边界采用一维河道模型计算得到,利用北部宜溧漕河下游段水文站(包括徐舍站等 3 个水位站, 每站相距约 $6 \mathrm{~km}$; 宜兴城内的 5 个流量站) 的同期实测资料计算分析得出北部水文边界条件,太湖边界采 用大浦口水文站的同期实测资料得到 ${ }^{[9]}$. 计算时间步长 $\Delta t$ 取为 $15 \mathrm{~min}$, 采用 1.2 .2 节所确定的参数, 对各 计算年限内典型河网区河网的水流变化情况进行计算模拟. 通过研究两条主要人湖河道林庄港与朱渎港 的水体流动规律, 分别对顺流与逆流情况下交换水量的年内分布与年际变化规律进行了分析.

\section{2 水量交换计算结果分析}

由计算所得林庄港、朱渎港的水量变化过程可知,在各计算年内,其顺流流态 (水流由河网区东人太 湖,包括滞流流态) 发生比例较高(约占全年的 $80 \%-90 \%$ ), 逆流流态 (即太湖水位升高时造成河道流向变 

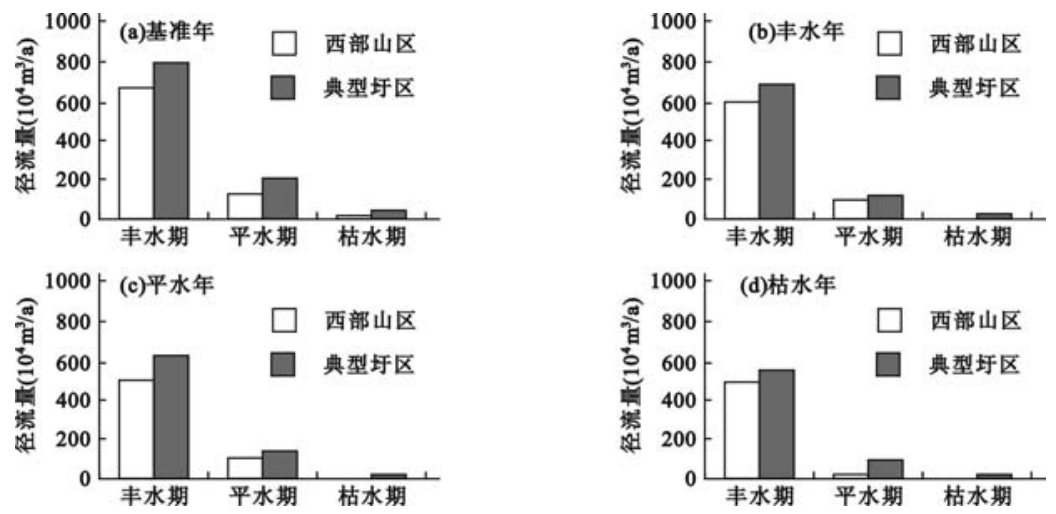

图 4 径流计算结果

Fig. 4 Results of the runoff modeling

向) 发生比例较低(约为 $10 \%-20 \%$ ), 由河网区东人太湖为常年主导流向.

顺流情况下 (图 5), 经由林庄港、朱渎港东人太湖的人湖水量约占河网区总出流水量(包括河网区汇人 东部太湖区与下游南部河网区的出流水量) 的 $25 \%-34 \%$, 且经由朱渎港的人湖水量大于经由林庄港的人 湖水量. 由丰水年至枯水年, 人湖水量次第减少,在年内河网区总出流水量中所占比例亦变小. 基准年人湖 水量最大,高于丰水年水平. 各年内丰水期人湖水量占全年人湖水量的比例均较高,约为 $52 \%-61 \%$.

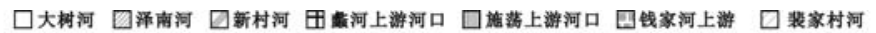

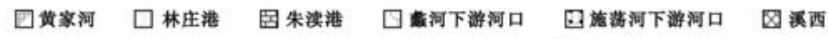
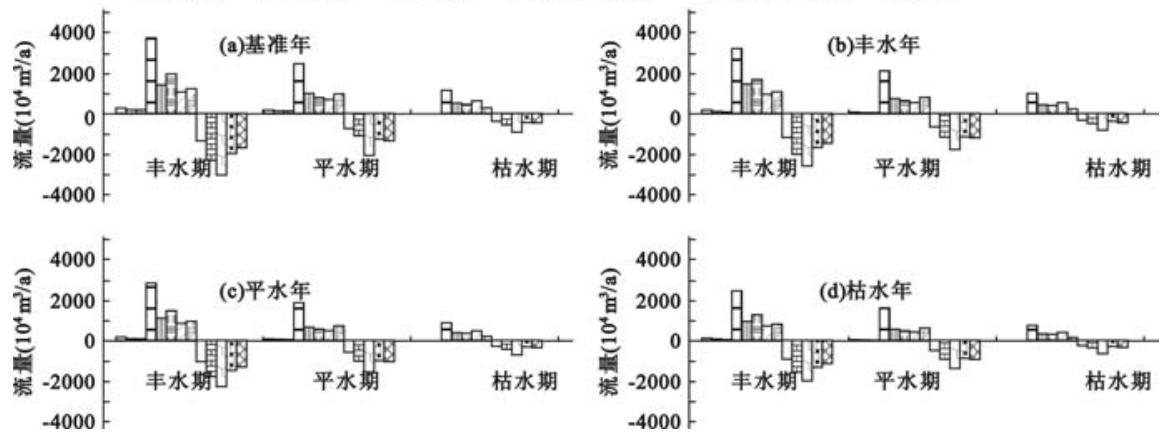

图 5 顺流情况下各主要河口计算水量

Fig. 5 Results of the water quantity modeling of the main rivers under co current

逆流情况下 (图 6), 经由林庄港、朱渎港进人河网区的倒灌水量约占逆向人河网区总水量 (包括东部太 湖区与下游南部河网区的逆向人流水量) 的 $28 \%-39 \%$, 且经由朱渎港的人流水量大于经由林庄港的人流 水量. 由丰水年至枯水年, 东部太湖倒灌水量次第增加,在年内逆流总水量中所占比例亦变大. 基准年的倒 灌水量最小. 各年内枯水期倒灌湖水量占全年逆流人河网区总水量的比例均较高,约为 $55 \%-68 \%$.

\section{4 结论}

考虑降雨因素的影响,利用产汇流模型计算模拟了各典型年中典型河网区及其西部山地区域的降雨径 流过程. 结合径流计算结果, 利用河网模型计算模拟了各典型年中典型河网区水流的动态变化, 从而系统 研究了典型河网区与太湖水体间的水量交换关系. 主要结论如下:

(1) 典型河网区自产水量与西部山区人流水量值于丰水年、平水年、枯水年内依次递减, 基准年内的值 最大;径流量主要集中发生于各年的丰水期内. 总体上典型河网区自产水量大于山区来水量. 


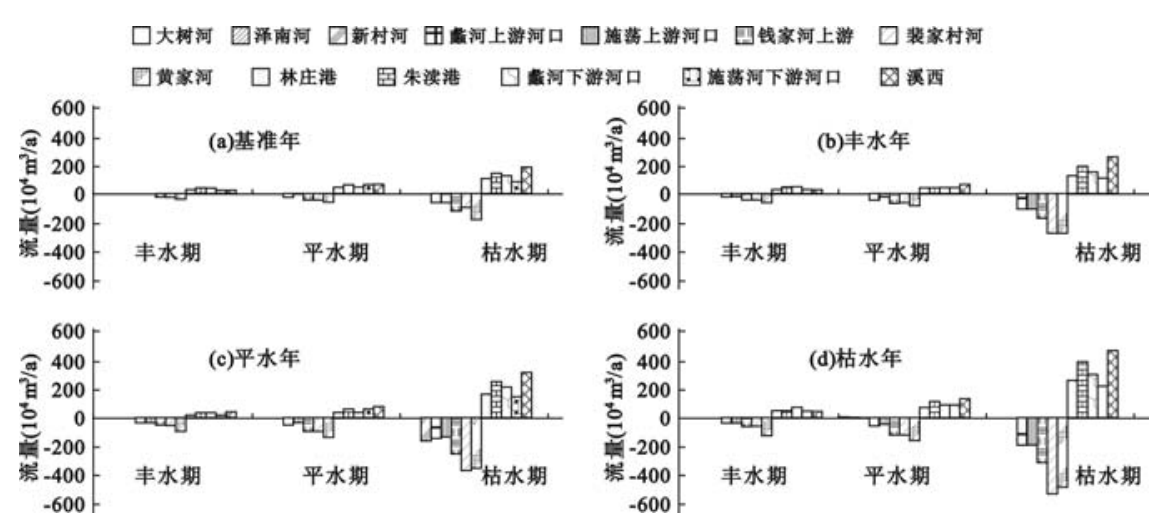

图 6 逆流情况下各主要河口计算水量( 说明同图 5)

Fig. 6 Results of the water quantity modeling of the main rivers under adverse current

(2) 林庄港与朱渎港为典型河网区主要的人湖河道,在研究典型河网区与太湖水量交换中有重要地 位. 林庄港、朱渎港的水量输送能力较强, 顺逆流情况下均输送相当数量的水流, 而以朱渎港作用更为显 著. 由丰水年至枯水年, 人湖水量次第减少; 东部太湖倒灌水量次第增加. 基准年的人湖水量最大, 枯水年 的倒灌水量最大.

(3) 水流由典型河网区东人太湖为常年的主导流向, 但逆流情况仍不容忽视, 东部太湖区的倒灌水量 亦不可忽略. 由于水流流态与污染物输移过程直接相关, 河网区内开展的工程措施尤其是湖口工程须充分 考虑湖水倒灌的影响.

(4) 该区域年内、年际水量分配很不均匀, 且典型河网区的降雨径流量较大,加之受西部山地来水影 响, 在河网区内实施河道生态、河道强化净化等工程措施时, 应充分考虑暴雨期间降雨径流产生的冲击 负荷.

(5) 典型河网区的逆流现象发生频次较高, 主要与太湖的风涌水过程有关 ${ }^{[13]}$. 在后续的研究工作中有 必要通过太湖风生流的数值计算, 对该区域风涌水过程进行详细分析.

\section{5 参考文献}

１1］许朋柱,秦伯强,黄文钰等. 太湖流域宜溧河地区水体水质状况及营养状态评价. 湖泊科学, 2001,13 (4) :315-321.

[2] 许朋柱,秦伯强. 2001-2002 水文年环太湖河道的水量及污染物通量. 湖泊科学, 2005,17(3):213-218.

[3] 罗 缙,逢 勇,罗清吉. 太湖流域平原河网区往复流河道水环境容量研究. 河海大学学报 (自然科学 版) ,2004, 32(2): $144-146$.

[4] 罗 缙, 逢 勇,林 颖等. 太湖流域主要人湖河道污染物通量研究. 河海大学学报 (自然科学版), $2005,33(2): 131-135$.

[5] 徐祖信, 卢士强. 平原感潮河网水动力模型研究. 水动力学研究与进展, 2001,18(2):176-181.

[6] 赵人俊. 流域水文模拟. 北京: 水利电力出版社, 1984: 131-138.

[7] 赵永军,杨 理, 程文辉. 太湖流域产汇流模拟. 河海大学学报 (自然科学版), 1998,26(2):110-113.

[8] 韩龙喜,陆 冬. 平原河网水流水质数值模拟研究展望. 河海大学学报 (自然科学版), 2004,32 (2): $127-130$.

[9] 李艈湘,逢 勇. 珠江三角洲地区河网水动力学模型研究. 水动力学研究与进展, 2001,16(2):143-155.

[10] 薛联青,张红举, 吕锡武. 感潮河道引江工程综合调度应用研究. 河海大学学报 (自然科学版),2003,33 (5) :668-672.

[11] 张二俊,张东升, 李 挺. 河网非恒定流的三级联合解法. 华东水利学院学报, 1982,10(1):1-13.

[12] 溪梅成. 数值分析方法. 合肥: 中国科学技术大学出版社, 1995:60-100.

[13] 逢 勇, 姚 琪, 兴培民. 太湖地区大气一水环境的综合数值研究. 北京:气象出版社, 1998:92-107. 